\title{
TCR Signaling Abnormalities in Human Th2-Associated Atopic Disease
}

\author{
Joshua D. Milner* \\ Laboratory of Allergic Diseases, National Institute of Allergy and Infectious Diseases (NIAID), National Institutes of Health \\ $(\mathrm{NIH})$, Bethesda, MD, United States
}

Stimulation of naive CD4 T cells with weak T cell receptor agonists even in the absence of $\mathrm{T}$ helper-skewing cytokines can result in IL-4 production which can drive a Th2 response. Evidence for the in vivo consequences of such a phenomenon can be found in a number of mouse models and, importantly, a series of monogenic human diseases associated with significant atopy which are caused by mutations in the T cell receptor signaling cascade. Such diseases can help understand how Th2 responses evolve in humans, and potentially provide insight into therapeutic interventions.

Keywords: T-cell receptor repertoire, signaling pathways, primary immunodeficiencies, atopic disease, monogenic syndromes

\section{INTRODUCTION}

OPEN ACCESS

Edited by:

Wanjun Chen,

National Institutes of Health (NIH),

United States

Reviewed by:

António Gil Castro,

University of Minho, Portugal

Lawrence Kane,

University of Pittsburgh,

United States

*Correspondence:

Joshua D. Milner

jdmilner@niaid.nih.gov

Specialty section:

This article was submitted

to T Cell Biology,

a section of the journal

Frontiers in Immunology

Received: 10 January 2018

Accepted: 22 March 2018

Published: 16 April 2018

Citation:

Milner JD (2018) TCR Signaling

Abnormalities in Human Th2-

Associated Atopic Disease.

Front. Immunol. 9:719.

doi: 10.3389/fimmu.2018.00719
Within the vast legacy of Bill Paul's career, one theme that emerged was the search for a source of IL-4 that would meaningfully provide differentiating naïve CD4 T cells sufficient signal to develop into memory Th2 cells during an immune response that required such a program. Mast cell (1), basophil (2-4), and NK T (5) IL-4 production were observed, but whether they are the key initiators of most Th2 responses continues to be a matter of debate. It was therefore in the course of that search that attention was turned to IL-4 production by the naïve T cell itself $(6,7)$. Kim Bottomly, herself a trainee of Bill's, had observed that in vitro priming of naive $\mathrm{T}$ cells by relatively weak, but not strong, agonist peptides, in the absence of other priming cytokines, could lead to a Th2 response (8-15). Bill's lab later showed that "strong" agonist peptides themselves could prime such a response, when provided at a sufficiently low dose (16), and that in lymphopenic states or when TCR of high affinity for a given peptide are removed, stimulated naïve cells will differentiate into Th2 cells $(17,18)$. The mechanisms for these observations continue to be unraveled, but include the notion that responses to IL-2 become blunted at higher dose of peptide, preventing the necessary STAT5b activation and nuclear translocation for transcription of key Th2 lineage transcription factor as well as poor ERK activation, as MEK inhibition could recapitulate the Th2 bias even in the presence of high dose strong TCR agonism $(9,16)$.

In vivo, indeed TCR/MHC interactions may even predominate over exogenous adjuvant activity in determining Th1/Th2 balance (19), although it may not always be via IL-4 production itself (20). One potential teleologic reason for the phenomenon could be that parasitic products which could evade immune responses by downregulating TCR-MHC interactions [such as the omega-1 component of schistosome egg antigen which can prime Th2 responses, potentially by weakening TCR/MHC interactions $(21,22)$ ] resulted in the evolution of anti-parasitic cytokine profiles which are derived from differentiation under low-affinity conditions. Whatever the cause, and whether IL-4 itself is the key driver of Th2 differentiation in vivo is a matter of debate, the success of IL-4 receptor blocking antibodies in treating human atopic disease has been impressive, strongly suggesting this pathway is critical for the pathogenesis of human atopic disease (23).

Another set of observations have further buttressed the notion that altered TCR signaling could lead to Th2 phenotypes. A series of mouse lines derived spontaneously or via random mutagenesis 
with missense mutations in key TCR signaling molecules were observed to develop Th2-related pathology spontaneously. These included LAT, ZAP70 (in several independent mutant lines), and CARMA1 (24-28). Null mutations in most of these molecules lead to impairment of effector function which precludes most Th differentiation altogether, and as such it is the hyopomorphic loss-of-function mutations which lead to the phenotype.

Of course, a major consequence of this basic observation could be that certain human disease could also be driven by this phenomenon and would most likely include an atopic phenotype. With the exponential growth of patients undergoing next-generation sequencing, multiple newly described immune disorders which include atopic disease have been identified, some of which may well be due to impaired TCR signaling. This review therefore provides a series of examples of human monogenic disorders associated with atopy which may be caused by imbalances in TCR signaling which fail to prevent Th2 responses.

\section{OMENN SYNDROME (OS)}

Before directly addressing the propensity for mutations to intrinsically bias a $\mathrm{T}$ cell toward Th2 differentiation, it is critical to distinguish one congenital atopic phenotype, namely, that seen in OS (29). Mutations that are known to lead to massive curtailment of $\mathrm{T}$ cell function and/or number-both intrinsic to signaling and extrinsic to it-can nonetheless permit "leaky" peripheral T cell populations which can progress to $\mathrm{CD} 4$ lymphoproliferation, organomegaly, and Th2-like disease associated with marked IgE elevation, erythroderma, and eosinophilia. Why OS is associated with the Th2 phenotype is not clear, but hypotheses have included a failure of central tolerance due to abnormal thymic development which hinders both AIRE-induced negative selection and the generation of a normal repertoire of FOXP3+ regulatory T cells (Tregs) (30-32). The lymphopenic state also may lead to the absence of sufficient high-affinity competition for antigen which would then permit low-affinity cells to be stimulated and proliferate, leading to the Th2 phenotype $(17,18)$.

\section{MUTATIONS IN GENES ENCODING CLASSICAL TCR SIGNALING PROTEINS}

Similar to the mouse, human mutations in ZAP70 can lead to varied phenotypes from SCID, to autoimmunity, to highly atopic phenotypes (33-37). In the case of one of the reported atopic phenotype in humans, it is not clear whether it was caused by intrinsic Th2 bias similar to the mouse model, or due to the limited repertoire associated with OS (35).

Stronger evidence for the link between TCR intrinsic signaling defects and atopy in human disease can be found in hypomorphic mutations of two members of the CBM complex, such as MALT1 (38) and CARMA1 $(39,40)$. The CBM complex, which includes MALT1, CARD11, and BCL10, is required for normal NFkB activation after TCR ligation, as well as MTORC1 activation (41, 42). Complete loss-of-function mutations of any of the three CBM complex members lead to a SCID-like illness (43-47), but recently, hypomorphic MALT1 mutations were described in a patient with recurrent infection, marked $\operatorname{IgE}$ elevation, and severe eczema (38). Even more recently, dominant-negative mutations leaving residual, hypomorphic CARD11 activity were identified in a cohort of patients with severe atopic disease with, and in some cases, without, comorbid infection. The finding is of particular interest since, in addition to the possibility that severe atopy without comorbidity could be explained by a single-gene mutation, CARD11 has been identified in GWAS studies of common atopic dermatitis (48).

While numerous patients with defects in nearly every NFkB subunit have been identified, atopy has not been reported to be associated with any of them. The lack of atopy argues that defects in another pathway in which CARD11 is involved might explain the allergic disease these patients have. Recent evidence suggests that CARD11 may also participate in mTORC1 activation (42) by recruiting, upregulating, and/or activating of the glutamine transporter ASCT2, which in turn leads to increased intracellular glutamine needed for mTORC1 activation. ASCT2-/- mice have a Th2 phenotype (49), potentially due to inadequate glutamine transport, which may be required for normal Th1 differentiation and the prevention of excessive Th2 differentiation $(50,51)$. The CARD11DN patients have evidence of impaired mTORC1 activation and reduced Th1 cytokine production, rescuable by exogenous glutamine (39), raising the possibility that glutamine supplementation could be of clinical benefit in these patients. Of note, glutamine supplementation of premature infants is associated with protection from the development of atopic dermatitis $(52,53)$.

\section{MUTATIONS IN GENES ENCODING ACTIN CYTOSKELETON PROTEINS}

Following TCR ligation, Wiskott-Aldrich syndrome protein (WASP) dissociates from its stabilizing partner WASP-interacting protein (WIP) and binds actin-related protein (ARP) 2/3 (54) to begin the actin assembly cascade.

Loss of WASP leads to Wiskott-Aldrich syndrome, which is characterized by severe atopic dermatitis, increased gut sensitization and clinical food allergy, thrombocytopenia, and combined immunodeficiency $(55,56)$. A similar phenotype occurs with loss of WASP-interacting protein family member 1 (WIPF1) encoding WIP (57) as well as an ARP2/3 subunit, actin-related protein 2/3 complex subunit 1B (ARPC1B) (58-60).

WASP-interacting protein also appears to associate with dedicator of cytokinesis 8 (DOCK8) a guanine nucleotide exchange factor whose activity is critical for normal WASP function (61). Loss of function in DOCK8 leads to significant elevations in IgE, combined immunodeficiency, and other many clinical features in common with WAS, including severe atopic dermatitis and food allergy, and even autoimmunity $(62,63)$. Thrombocytopenia is not seen in DOCK8 deficiency, while severe viral skin infections and anaphylaxis are not as common in WAS, potentially due to differences in redundancy, function, and tissue expression $(56,64,65)$.

Once again, we know less about why Th2 phenotypes emerge from these actin cytoskeleton-related mutations. DOCK8 patient lymphocytes have a $\mathrm{T}$ cell-intrinsic bias toward Th2, and away 
from Th1 differentiation (66), and WASP transcriptional activity appears to be critical for Th1 differentiation $(67,68)$. Another possible mechanism suggests these proteins have critical roles in Treg function, potentially via IL-2 activity, the impairment of which therefore would lead to immune dysregulation of all types, including Th2 (56, 69-73).

On this point, it is important to note that Treg failure is always a consideration when trying to understand how impaired TCR signaling could lead to Th2 phenotypes, since an ideal TCR signal is necessary for normal Treg development, differentiation, and function (74). While CARD11DN patient Tregs appeared quantitatively and qualitatively normal, the mouse model suggested otherwise (26). It is further noteworthy that while the mechanism of weak TCR signal failing to curtail STAT5b activity has not yet been studied in the human TCR signaling defects, gain-offunction missense mutations in STAT5b, and JAK1-which activates STAT5b-are associated with syndromes characterized by profound early onset dermatitis and eosinophilia $(75,76)$. That said, while STAT5bGOF mutations lead to a Th2 phenotype, so too can STAT5bLOF mutations, which are associated with severe Treg impairment (77). While in humans it is difficult to tease apart the relative contributions of effector $\mathrm{T}$ cell intrinsic predisposition toward Th2 responses and responsiveness to extrinsic regulation from the number and function of Tregs themselves, it is still important to study both in the context of human diseases of impaired TCR signaling.

\section{CONCLUSION}

A great deal remains unknown or unproven with respect to the direct role for TCR signaling defects and/or weak TCR signaling

\section{REFERENCES}

1. Plaut M, Pierce JH, Watson CJ, Hanley-Hyde J, Nordan RP, Paul WE. Mast cell lines produce lymphokines in response to cross-linkage of Fc epsilon RI or to calcium ionophores. Nature (1989) 339(6219):64-7. doi:10.1038/ $339064 \mathrm{a} 0$

2. Ben-Sasson SZ, Le Gros G, Conrad DH, Finkelman FD, Paul WE. Crosslinking Fc receptors stimulate splenic non-B, non-T cells to secrete interleukin 4 and other lymphokines. Proc Natl Acad Sci U S A (1990) 87(4):1421-5. doi:10.1073/pnas.87.4.1421

3. SederRA,PaulWE,Ben-SassonSZ,LeGrosGS, Kagey-SobotkaA, FinkelmanFD, et al. Production of interleukin-4 and other cytokines following stimulation of mast cell lines and in vivo mast cells/basophils. Int Arch Allergy Appl Immunol (1991) 94(1-4):137-40. doi:10.1159/000235345

4. Seder RA, Paul WE, Dvorak AM, Sharkis SJ, Kagey-Sobotka A, Niv Y, et al. Mouse splenic and bone marrow cell populations that express high-affinity Fc epsilon receptors and produce interleukin 4 are highly enriched in basophils. Proc Natl Acad Sci U S A (1991) 88(7):2835-9. doi:10.1073/pnas. 88.7.2835

5. Yoshimoto T, Bendelac A, Watson C, Hu-Li J, Paul WE. Role of NK1.1+ T cells in a TH2 response and in immunoglobulin E production. Science (1995) 270(5243):1845-7. doi:10.1126/science.270.5243.1845

6. Ben-Sasson SZ, Le Gros G, Conrad DH, Finkelman FD, Paul WE. IL-4 production by $\mathrm{T}$ cells from naive donors. IL-2 is required for IL-4 production. J Immunol (1990) 145(4):1127-36.

7. Le Gros G, Ben-Sasson SZ, Seder R, Finkelman FD, Paul WE. Generation of interleukin 4 (IL-4)-producing cells in vivo and in vitro: IL-2 and IL-4 are required for in vitro generation of IL-4-producing cells. J Exp Med (1990) 172(3):921-9. doi:10.1084/jem.172.3.921 in human allergic disease. The limitations which exist when studying human $\mathrm{T}$ helper differentiation make it harded to directly demonstrate causality. However, the preponderance of evidence coupling mouse and human in vitro studies with ex vivo human studies suggests disruption of a number of TCR signaling pathways could well lead to a Th2 phenotype which in turn drives an organismal atopic disease. Apart from the mechanistic insight this provides, how such knowledge could be translated into positive therapeutic manipulation remains a question. Balancing the therapeutic manipulation with risk and cost is of course key. While indeed targeting Th2 cytokines has been quite successful in the clinic, the use of such medications is still in its early phases, and they are extremely expensive. Of course, depending on the severity of disease, bone marrow transplant can be an option, and in theory so could gene therapy and/or gene editing. Other interventions meant to strengthen TCR signaling always run the risk of leaning toward aberrant autoreactivity as well. The ultimate consequences of these balances and their perturbation will be gleaned from continued mechanistic research into the precise mechanisms by which the Th2 phenotypic program emerges when TCR signaling is impaired.

\section{AUTHOR CONTRIBUTIONS}

The author confirms being the sole contributor of this work and approved it for publication.

\section{ACKNOWLEDGMENTS}

This study was supported by the intramural research program of the NIAID, NIH.

8. Constant SL, Bottomly K. Induction of Th1 and Th2 CD4+ T cell responses: the alternative approaches. Annu Rev Immunol (1997) 15:297-322. doi:10.1146/ annurev.immunol.15.1.297

9. Yamane H, Paul WE. Early signaling events that underlie fate decisions of naive CD4(+) T cells toward distinct T-helper cell subsets. Immunol Rev (2013) 252(1):12-23. doi:10.1111/imr.12032

10. Boutin Y, Leitenberg D, Tao X, Bottomly K. Distinct biochemical signals characterize agonist- and altered peptide ligand-induced differentiation of naive CD4+ T cells into Th1 and Th2 subsets. J Immunol (1997) 159(12):5802-9.

11. Tao X, Constant S, Jorritsma P, Bottomly K. Strength of TCR signal determines the costimulatory requirements for Th1 and Th2 CD4+ T cell differentiation. J Immunol (1997) 159(12):5956-63.

12. Leitenberg D, Boutin Y, Constant S, Bottomly K. CD4 regulation of TCR signaling and $\mathrm{T}$ cell differentiation following stimulation with peptides of different affinities for the TCR. J Immunol (1998) 161(3):1194-203.

13. Hosken NA, Shibuya K, Heath AW, Murphy KM, O'Garra A. The effect of antigen dose on CD4+ $\mathrm{T}$ helper cell phenotype development in a $\mathrm{T}$ cell receptor-alpha beta-transgenic model. J Exp Med (1995) 182(5):1579-84. doi:10.1084/jem.182.5.1579

14. Tao X, Grant C, Constant S, Bottomly K. Induction of IL-4-producing CD4+ $\mathrm{T}$ cells by antigenic peptides altered for TCR binding. J Immunol (1997) 158(9):4237-44.

15. Jorritsma PJ, Brogdon JL, Bottomly K. Role of TCR-induced extracellular signal-regulated kinase activation in the regulation of early IL-4 expression in naive CD4+ T cells. J Immunol (2003) 170(5):2427-34. doi:10.4049/ jimmunol.170.5.2427

16. Yamane H, Zhu J, Paul WE. Independent roles for IL-2 and GATA-3 in stimulating naive CD4+ T cells to generate a Th2-inducing cytokine environment. J Exp Med (2005) 202(6):793-804. doi:10.1084/jem.20051304 
17. Milner JD, Ward JM, Keane-Myers A, Paul WE. Lymphopenic mice reconstituted with limited repertoire $\mathrm{T}$ cells develop severe, multiorgan, Th2-associated inflammatory disease. Proc Natl Acad Sci U S A (2007) 104(2):576-81. doi:10.1073/pnas.0610289104

18. Milner JD, Fazilleau N, McHeyzer-Williams M, Paul W. Cutting edge: lack of high affinity competition for peptide in polyclonal CD4+ responses unmasks IL-4 production. J Immunol (2010) 184(12):6569-73. doi:10.4049/ jimmunol.1000674

19. van Panhuys N, Klauschen F, Germain RN. T-cell-receptor-dependent signal intensity dominantly controls $\mathrm{CD} 4(+) \mathrm{T}$ cell polarization in vivo. Immunity (2014) 41(1):63-74. doi:10.1016/j.immuni.2014.06.003

20. van Panhuys N, Tang SC, Prout M, Camberis M, Scarlett D, Roberts J, et al. In vivo studies fail to reveal a role for IL-4 or STAT6 signaling in Th2 lymphocyte differentiation. Proc Natl Acad Sci U S A (2008) 105(34):12423-8. doi:10.1073/ pnas. 0806372105

21. Everts B, Perona-Wright G, Smits HH, Hokke CH, van der Ham AJ, Fitzsimmons CM, et al. Omega-1, a glycoprotein secreted by Schistosoma mansoni eggs, drives Th2 responses. J Exp Med (2009) 206(8):1673-80. doi:10.1084/ jem. 20082460

22. Steinfelder S, Andersen JF, Cannons JL, Feng CG, Joshi M, Dwyer D, et al. The major component in schistosome eggs responsible for conditioning dendritic cells for Th2 polarization is a T2 ribonuclease (omega-1). J Exp Med (2009) 206(8):1681-90. doi:10.1084/jem.20082462

23. Chang HY, Nadeau KC. IL-4Ralpha inhibitor for atopic disease. Cell (2017) 170(2):222. doi:10.1016/j.cell.2017.06.046

24. Jakob T, Kollisch GV, Howaldt M, Bewersdorff M, Rathkolb B, Muller ML, et al. Novel mouse mutants with primary cellular immunodeficiencies generated by genome-wide mutagenesis. J Allergy Clin Immunol (2008) 121(1):179-84.e7. doi:10.1016/j.jaci.2007.07.018

25. Mingueneau M, Roncagalli R, Gregoire C, Kissenpfennig A, Miazek A, Archambaud C, et al. Loss of the LAT adaptor converts antigen-responsive $\mathrm{T}$ cells into pathogenic effectors that function independently of the $\mathrm{T}$ cell receptor. Immunity (2009) 31(2):197-208. doi:10.1016/j.immuni.2009.05.013

26. Jun JE, Wilson LE, Vinuesa CG, Lesage S, Blery M, Miosge LA, et al. Identifying the MAGUK protein Carma-1 as a central regulator of humoral immune responses and atopy by genome-wide mouse mutagenesis. Immunity (2003) 18(6):751-62. doi:10.1016/S1074-7613(03)00141-9

27. Siggs OM, Miosge LA, Yates AL, Kucharska EM, Sheahan D, Brdicka T, et al. Opposing functions of the T cell receptor kinase ZAP-70 in immunity and tolerance differentially titrate in response to nucleotide substitutions. Immunity (2007) 27(6):912-26. doi:10.1016/j.immuni.2007.11.013

28. Aguado E, Richelme S, Nunez-Cruz S, Miazek A, Mura AM, Richelme M, et al. Induction of Thelper type 2 immunity by a point mutation in the LAT adaptor. Science (2002) 296(5575):2036-40. doi:10.1126/science.1069057

29. Omenn GS. Familial reticuloendotheliosis with eosinophilia. N Engl J Med (1965) 273:427-32. doi:10.1056/NEJM196508192730806

30. Cavadini P, Vermi W, Facchetti F, Fontana S, Nagafuchi S, Mazzolari E, et al. AIRE deficiency in thymus of 2 patients with Omenn syndrome. J Clin Invest (2005) 115(3):728-32. doi:10.1172/JCI200523087

31. Marrella V, Poliani PL, Casati A, Rucci F, Frascoli L, Gougeon ML, et al. A hypomorphic R229Q Rag2 mouse mutant recapitulates human Omenn syndrome. J Clin Invest (2007) 117(5):1260-9. doi:10.1172/JCI30928

32. Poliani PL, Facchetti F, Ravanini M, Gennery AR, Villa A, Roifman CM, et al. Early defects in human T-cell development severely affect distribution and maturation of thymic stromal cells: possible implications for the pathophysiology of Omenn syndrome. Blood (2009) 114(1):105-8. doi:10.1182/ blood-2009-03-211029

33. Chan AC, Kadlecek TA, Elder ME, Filipovich AH, Kuo WL, Iwashima M, et al. ZAP-70 deficiency in an autosomal recessive form of severe combined immunodeficiency. Science (1994) 264(5165):1599-601. doi:10.1126/ science. 8202713

34. Arpaia E, Shahar M, Dadi H, Cohen A, Roifman CM. Defective T cell receptor signaling and CD8+ thymic selection in humans lacking zap-70 kinase. Cell (1994) 76(5):947-58. doi:10.1016/0092-8674(94)90368-9

35. Turul T, Tezcan I, Artac H, de Bruin-Versteeg S, Barendregt BH, Reisli I, et al. Clinical heterogeneity can hamper the diagnosis of patients with ZAP70 deficiency. Eur J Pediatr (2009) 168(1):87-93. doi:10.1007/s00431-008-0718-x
36. Picard C, Dogniaux S, Chemin K, Maciorowski Z, Lim A, Mazerolles F, et al. Hypomorphic mutation of ZAP70 in human results in a late onset immunodeficiency and no autoimmunity. Eur J Immunol (2009) 39(7):1966-76. doi:10.1002/eji.200939385

37. Elder ME, Lin D, Clever J, Chan AC, Hope TJ, Weiss A, et al. Human severe combined immunodeficiency due to a defect in ZAP-70, a T cell tyrosine kinase. Science (1994) 264(5165):1596-9. doi:10.1126/science.8202712

38. McKinnon ML, Rozmus J, Fung SY, Hirschfeld AF, Del Bel KL, Thomas L, et al. Combined immunodeficiency associated with homozygous MALT1 mutations. J Allergy Clin Immunol (2014) 133(5):.1458-.1462. doi:10.1016/j. jaci.2013.10.045

39. Ma CA, Stinson JR, Zhang Y, Abbott JK, Weinreich MA, Hauk PJ, et al. Germline hypomorphic CARD11 mutations in severe atopic disease. Nat Genet (2017) 49(8):1192-201. doi:10.1038/ng.3898

40. Dadi H, Jones TA, Merico D, Sharfe N, Ovadia A, Schejter Y, et al. Combined immunodeficiency and atopy caused by a dominant negative mutation in caspase activation and recruitment domain family member 11 (CARD11). J Allergy Clin Immunol (2017). doi:10.1016/j.jaci.2017.06.047

41. Bertin J, Wang L, Guo Y, Jacobson MD, Poyet JL, Srinivasula SM, et al. CARD11 and CARD14 are novel caspase recruitment domain (CARD)/membrane-associated guanylate kinase (MAGUK) family members that interact with BCL10 and activate NF-kappa B. J Biol Chem (2001) 276(15):11877-82. doi:10.1074/jbc.M010512200

42. Hamilton KS, Phong B, Corey C, Cheng J, Gorentla B, Zhong X, et al. T cell receptor-dependent activation of mTOR signaling in T cells is mediated by Carma1 and MALT1, but not Bcl10. Sci Signal (2014) 7(329):ra55. doi:10.1126/ scisignal.2005169

43. Greil J, Rausch T, Giese T, Bandapalli OR, Daniel V, Bekeredjian-Ding I, et al. Whole-exome sequencing links caspase recruitment domain 11 (CARD11) inactivation to severe combined immunodeficiency. J Allergy Clin Immunol (2013) 131(5):1376-83.e3. doi:10.1016/j.jaci.2013.02.012

44. Stepensky P, Keller B, Buchta M, Kienzler AK, Elpeleg O, Somech R, et al. Deficiency of caspase recruitment domain family, member 11 (CARD11), causes profound combined immunodeficiency in human subjects. J Allergy Clin Immunol (2013) 131(2):477-85.e1. doi:10.1016/j.jaci.2012.11.050

45. Jabara HH, Ohsumi T, Chou J, Massaad MJ, Benson H, Megarbane A, et al. A homozygous mucosa-associated lymphoid tissue 1 (MALT1) mutation in a family with combined immunodeficiency. J Allergy Clin Immunol (2013) 132(1):151-8. doi:10.1016/j.jaci.2013.04.047

46. Punwani D, Wang H, Chan AY, Cowan MJ, Mallott J, Sunderam U, et al. Combined immunodeficiency due to MALT1 mutations, treated by hematopoietic cell transplantation. J Clin Immunol (2015) 35(2):135-46. doi:10.1007/ s10875-014-0125-1

47. Torres JM, Martinez-Barricarte R, Garcia-Gomez S, Mazariegos MS, Itan Y, Boisson B, et al. Inherited BCL10 deficiency impairs hematopoietic and nonhematopoietic immunity. J Clin Invest (2014) 124(12):5239-48. doi:10.1172/ JCI77493

48. Hirota T, Takahashi A, Kubo M, Tsunoda T, Tomita K, Sakashita M, et al. Genome-wide association study identifies eight new susceptibility loci for atopic dermatitis in the Japanese population. Nat Genet (2012) 44(11):1222-6. doi:10.1038/ng.2438

49. Nakaya M, Xiao Y, Zhou X, Chang JH, Chang M, Cheng X, et al. Inflammatory $\mathrm{T}$ cell responses rely on amino acid transporter ASCT2 facilitation of glutamine uptake and mTORC1 kinase activation. Immunity (2014) 40(5):692-705. doi:10.1016/j.immuni.2014.04.007

50. Delgoffe GM, Pollizzi KN, Waickman AT, Heikamp E, Meyers DJ, Horton MR, et al. The kinase mTOR regulates the differentiation of helper T cells through the selective activation of signaling by mTORC1 and mTORC2. Nat Immunol (2011) 12(4):295-303. doi:10.1038/ni.2005

51. Chornoguz O, Hagan RS, Haile A, Arwood ML, Gamper CJ, Banerjee A, et al. mTORC1 promotes T-bet phosphorylation to regulate Th1 differentiation. J Immunol (2017) 198(10):3939-48. doi:10.4049/jimmunol.1601078

52. van den Berg A, van Zwol A, Moll HA, Fetter WP, van Elburg RM. Glutamineenriched enteral nutrition in very low-birth-weight infants: effect on the incidence of allergic and infectious diseases in the first year of life. Arch Pediatr Adolesc Med (2007) 161(11):1095-101. doi:10.1001/archpedi.161. 11.1095 
53. van Zwol A, Moll HA, Fetter WP, van Elburg RM. Glutamine-enriched enteral nutrition in very low birthweight infants and allergic and infectious diseases at 6 years of age. Paediatr Perinat Epidemiol (2011) 25(1):60-6. doi:10.1111/j.1365-3016.2010.01173.x

54. Zigmond SH. How WASP regulates actin polymerization. J Cell Biol (2000) 150(6):F117-20. doi:10.1083/jcb.150.6.F117

55. Ochs HD. Mutations of the Wiskott-Aldrich syndrome protein affect protein expression and dictate the clinical phenotypes. Immunol Res (2009) 44(1-3):84-8. doi:10.1007/s12026-008-8084-3

56. Lexmond WS, Goettel JA, Lyons JJ, Jacobse J, Deken MM, Lawrence MG, et al. FOXP3+ Tregs require WASP to restrain Th2-mediated food allergy. J Clin Invest (2016) 126(10):4030-44. doi:10.1172/JCI85129

57. Lanzi G, Moratto D, Vairo D, Masneri S, Delmonte O, Paganini T, et al. A novel primary human immunodeficiency due to deficiency in the WASP-interacting protein WIP. J Exp Med (2012) 209(1):29-34. doi:10.1084/jem.20110896

58. Kuijpers TW, Tool ATJ, van der Bijl I, de Boer M, van Houdt M, de Cuyper IM, et al. Combined immunodeficiency with severe inflammation and allergy caused by ARPC1B deficiency. J Allergy Clin Immunol (2017) 140(1):273-7. e10. doi:10.1016/j.jaci.2016.09.061

59. Kahr WH, Pluthero FG, Elkadri A, Warner N, Drobac M, Chen CH, et al. Loss of the Arp2/3 complex component ARPC1B causes platelet abnormalities and predisposes to inflammatory disease. Nat Commun (2017) 8:14816. doi:10.1038/ncomms14816

60. Somech R, Lev A, Lee YN, Simon AJ, Barel O, Schiby G, et al. Disruption of thrombocyte and T lymphocyte development by a mutation in ARPC1B. J Immunol (2017) 199(12):4036-45. doi:10.4049/jimmunol.1700460

61. Janssen E, Tohme M, Hedayat M, Leick M, Kumari S, Ramesh N, et al. A DOCK8-WIP-WASp complex links T cell receptors to the actin cytoskeleton. J Clin Invest (2016) 126(10):3837-51. doi:10.1172/JCI85774

62. Zhang Q, Davis JC, Lamborn IT, Freeman AF, Jing H, Favreau AJ, et al. Combined immunodeficiency associated with DOCK8 mutations. $N$ Engl J Med (2009) 361(21):2046-55. doi:10.1056/NEJMoa0905506

63. Aydin SE, Kilic SS, Aytekin C, Kumar A, Porras O, Kainulainen L, et al. DOCK8 deficiency: clinical and immunological phenotype and treatment options - a review of 136 patients. J Clin Immunol (2015) 35(2):189-98. doi:10.1007/s10875-014-0126-0

64. Ogawa K, Tanaka Y, Uruno T, Duan X, Harada Y, Sanematsu F, et al. DOCK5 functions as a key signaling adaptor that links FcepsilonRI signals to microtubule dynamics during mast cell degranulation. J Exp Med (2014) 211(7):1407-19. doi:10.1084/jem.20131926

65. Pivniouk VI, Snapper SB, Kettner A, Alenius H, Laouini D, Falet H, et al. Impaired signaling via the high-affinity $\operatorname{IgE}$ receptor in Wiskott-Aldrich syndrome protein-deficient mast cells. Int Immunol (2003) 15(12):1431-40. doi:10.1093/intimm/dxg148

66. Tangye SG, Pillay B, Randall KL, Avery DT, Phan TG, Gray P, et al. Dedicator of cytokinesis 8-deficient CD4(+) T cells are biased to a TH2 effector fate at the expense of TH1 and TH17 cells. J Allergy Clin Immunol (2017) 139(3):933-49. doi:10.1016/j.jaci.2016.07.016

67. Taylor MD, Sadhukhan S, Kottangada P, Ramgopal A, Sarkar K, D’Silva S, et al. Nuclear role of WASp in the pathogenesis of dysregulated TH1 immunity in human Wiskott-Aldrich syndrome. Sci Transl Med (2010) 2(37):37ra44. doi:10.1126/scitranslmed.3000813
68. Sarkar K, Han SS, Wen KK, Ochs HD, Dupre L, Seidman MM, et al. R-loops cause genomic instability in Wiskott-Aldrich syndrome Thelper lymphocytes. J Allergy Clin Immunol (2017). doi:10.1016/j.jaci.2017.11.023

69. Alroqi FJ, Charbonnier LM, Keles S, Ghandour F, Mouawad P, Sabouneh R, et al. DOCK8 deficiency presenting as an IPEX-like disorder. J Clin Immunol (2017) 37(8):811-9. doi:10.1007/s10875-017-0451-1

70. Humblet-Baron S, Sather B, Anover S, Becker-Herman S, Kasprowicz DJ, Khim $S$, et al. Wiskott-Aldrich syndrome protein is required for regulatory T cell homeostasis. J Clin Invest (2007) 117(2):407-18. doi:10.1172/ JCI29539

71. Maillard MH, Cotta-de-Almeida V, Takeshima F, Nguyen DD, Michetti P, Nagler C, et al. The Wiskott-Aldrich syndrome protein is required for the function of CD4(+)CD25(+)Foxp3(+) regulatory T cells. J Exp Med (2007) 204(2):381-91. doi:10.1084/jem.20061338

72. Marangoni F, Trifari S, Scaramuzza S, Panaroni C, Martino S, Notarangelo LD, et al. WASP regulates suppressor activity of human and murine CD4(+) CD25(+)FOXP3(+) natural regulatory T cells. J Exp Med (2007) 204(2):36980. doi:10.1084/jem.20061334

73. Singh AK, Eken A, Hagin D, Komal K, Bhise G, Shaji A, et al. DOCK8 regulates fitness and function of regulatory $\mathrm{T}$ cells through modulation of IL-2 signaling. JCI Insight (2017) 2(19). doi:10.1172/jci.insight.94275

74. Li MO, Rudensky AY. T cell receptor signalling in the control of regulatory $\mathrm{T}$ cell differentiation and function. Nat Rev Immunol (2016) 16(4):220-33. doi:10.1038/nri.2016.26

75. Ma CA, Xi L, Cauff B, DeZure A, Freeman AF, Hambleton S, et al. Somatic STAT5b gain-of-function mutations in early onset nonclonal eosinophilia, urticaria, dermatitis, and diarrhea. Blood (2017) 129(5):650-3. doi:10.1182/ blood-2016-09-737817

76. Del Bel KL, Ragotte RJ, Saferali A, Lee S, Vercauteren SM, Mostafavi SA, et al. JAK1 gain-of-function causes an autosomal dominant immune dysregulatory and hypereosinophilic syndrome. J Allergy Clin Immunol (2017) 139(6):2016-20.e5. doi:10.1016/j.jaci.2016.12.957

77. Cohen AC, Nadeau KC, Tu W, Hwa V, Dionis K, Bezrodnik L, et al. Cutting edge: decreased accumulation and regulatory function of CD4+ CD25(high) T cells in human STAT5b deficiency. J Immunol (2006) 177(5):2770-4. doi:10.4049/jimmunol.177.5.2770

Conflict of Interest Statement: The author declares that the research was conducted in the absence of any commercial or financial relationships that could be construed as a potential conflict of interest.

The handling Editor declared a shared affiliation, though no other collaboration, with the author.

Copyright (C) 2018 Milner. This is an open-access article distributed under the terms of the Creative Commons Attribution License (CC BY). The use, distribution or reproduction in other forums is permitted, provided the original author(s) and the copyright owner are credited and that the original publication in this journal is cited, in accordance with accepted academic practice. No use, distribution or reproduction is permitted which does not comply with these terms. 